\title{
Interplay between estrogen receptor and AKT in Estradiol-induced alternative splicing
}

\author{
Poornima Bhat-Nakshatri ${ }^{1}$, Eun-Kyung Song ${ }^{1}$, Nikail R Collins' ${ }^{1}$, Vladimir N Uversky ${ }^{3,7}$, A Keith Dunker ${ }^{3,4}$, \\ Bert W O'Malley ${ }^{5}$, Tim R Geistlinger ${ }^{6,8}$, Jason S Carroll ${ }^{6,9}$, Myles Brown ${ }^{6}$ and Harikrishna Nakshatri ${ }^{1,2^{*}}$
}

\begin{abstract}
Background: Alternative splicing is critical for generating complex proteomes in response to extracellular signals. Nuclear receptors including estrogen receptor alpha (ERa) and their ligands promote alternative splicing. The endogenous targets of ERa:estradiol (E2)-mediated alternative splicing and the influence of extracellular kinases that phosphorylate ERa on E2-induced splicing are unknown.

Methods: MCF-7 and its anti-estrogen derivatives were used for the majority of the assays. CD44 mini gene was used to measure the effect of E2 and AKT on alternative splicing. ExonHit array analysis was performed to identify E2 and AKT-regulated endogenous alternatively spliced apoptosis-related genes. Quantitative reverse transcription polymerase chain reaction was performed to verify alternative splicing. ERa binding to alternatively spliced genes was verified by chromatin immunoprecipitation assay. Bromodeoxyuridine incorporation-ELISA and Annexin V labeling assays were done to measure cell proliferation and apoptosis, respectively.

Results: We identified the targets of E2-induced alternative splicing and deconstructed some of the mechanisms surrounding E2-induced splicing by combining splice array with ERa cistrome and gene expression array. E2induced alternatively spliced genes fall into at least two subgroups: coupled to E2-regulated transcription and ERa binding to the gene without an effect on rate of transcription. Further, AKT, which phosphorylates both ERa and splicing factors, influenced ERa:E2 dependent splicing in a gene-specific manner. Genes that are alternatively spliced include FAS/CD95, FGFR2, and AXIN-1. E2 increased the expression of FGFR2 C1 isoform but reduced C3 isoform at mRNA level. E2-induced alternative splicing of FAS and FGFR2 in MCF-7 cells correlated with resistance to FAS activation-induced apoptosis and response to keratinocyte growth factor (KGF), respectively. Resistance of MCF-7 breast cancer cells to the anti-estrogen tamoxifen was associated with ERa-dependent overexpression of FGFR2, whereas resistance to fulvestrant was associated with ERa-dependent isoform switching, which correlated with altered response to KGF.
\end{abstract}

Conclusion: E2 may partly alter cellular proteome through alternative splicing uncoupled to its effects on transcription initiation and aberration in E2-induced alternative splicing events may influence response to anti-estrogens.

\section{Background}

Estradiol (E2) signaling primarily involves activation of nuclear receptors, estrogen receptors alpha $(E R \alpha)$ and beta $(E R \beta)$, which function as transcription factors that regulate gene expression through either DNA binding or through protein-protein interaction [1,2]. E2 signaling in

\footnotetext{
* Correspondence: hnakshat@iupui.edu

'Departments of Surgery, Indiana University School of Medicine, 980 West Walnut Street, Indianapolis, IN 46202, USA

${ }^{2}$ Biochemistry and Molecular Biology, Indiana University School of Medicine, Indianapolis, IN 46202, USA

Full list of author information is available at the end of the article
}

cells is further controlled by several post-transcriptional modifications of ER $\alpha$ and ER $\beta$ including phosphorylation, acetylation, and ubiquitination. These posttranscriptional events influence the ability of $E R \alpha$ to interact with co-regulator molecules, its stability, and localization. Kinases known to phosphorylate ER $\alpha$ include MAPK, IKK $\alpha$, RSK, AKT/PKB, p38 kinase, PKA, Src, cyclin $\mathrm{A} / \mathrm{cdk} 2$, and cdk7 [1,3-7]. It is suggested that changes in the phosphorylation status of the receptor contribute to ER $\alpha$ dysfunction in various pathological conditions including breast cancer.

\section{Biomed Central}


Alternative splicing is an important post-transcriptional mechanism that permits the generation of multiple protein products from a single gene. $92-94 \%$ of human genes undergo alternative splicing and 70-90\% of these spliced RNAs are translated into proteins $[8,9]$. A recent genomewide sequencing indicated 22,000 tissue-specific alternative splicing events [8]. Two families of splicing factors have been identified: heterogeneous nuclear ribonucleoprotein (hnRNP) related proteins and the serine-arginine rich (SR) proteins $[9,10]$. Phosphorylation controls activity of these proteins $[9,10]$. For example, RS domains of SR proteins contain multiple copies of consensus AKT phosphorylation site RXRXXS and AKT controls their activity in the nucleus and cytoplasm [11].

Defects in alternative splicing are linked to various diseases including spinal muscular atrophy, neurofibromatosis type 1 , cystic fibrosis, breast cancer, and ovarian cancer [12,13]. For example, alternative splicing can change CC3, which codes for a protein with antimetastatic and pro-apoptotic properties, to TC3, which codes for a protein with pro-metastatic and antiapoptotic properties [14]. Alternative splicing of the transcription factor FOXP1 influences pluripotency and differentiation of embryonic stem cells [15]. At least 15\% of human genetic diseases arise from mutations either in consensus splice sites or in splicing silencer or enhancer elements [12]. Cancer-associated alternative splicing, which is regulated by FOX1, FOX2, and Nova proteins, has been reported [16,17]. These alternative splicing events empower cancer cells to express developmentally regulated proteins [13]. Breast cancer subtypes show distinct splicing pattern, which may partly be related to FOX1/FOX2 expression [16,18]. Genetic alterations in splicing machinery is linked to myelodysplasia [19]. Recent studies using bioinformatics tools including intrinsic disorder predictions have shown that alternative splicing is a non-random event and often involves the region of the protein engaged in protein-protein interaction [20]. Thus, loss or gain of exons through alternative splicing has major functional implications.

A clear link between steroid regulated transcription and alternative splicing has been established [21]. At least 25 proteins have been described to have both transcription coregulator and splicing activity [22]. Proteins involved in steroid-regulated alternative splicing events include U2AF65-related proteins CAPER $\alpha$ and CAPER $\beta$, ASC-1, ASC-2, and CoAA [23]. Several of these molecules interact directly with ER $\alpha$. ER $\alpha$ :E2 controls transcription-coupled alternative splicing of the first intron in a gene specific manner, which impacts the rate of co-transcriptional RNA processing [24]. However, whether these ER $\alpha$ :splicing factor interactions contribute to breast cancer subtype-enriched alternative splicing or whether ER $\alpha$ :E2 induces alternative splicing uncoupled to transcription initiation activity, is yet to be determined. Additionally, there are limited number of reports that have examined the effect of ER $\alpha$ phosphorylation on alternative splicing [25]. ER $\alpha$ phosphorylated at S118 by MAPKs interacts with the splicing factor SF3a, a component of U2 snRNP complex, and promotes exon skipping [25].

We had previously shown the effects of AKT on ER $\alpha$ : E2 mediated transcription, which correlated with the phosphorylation of S167 residue of ER $\alpha$ [6]. Crosstalk between ER $\alpha$ and AKT is likely to play a significant role in $\mathrm{ER} \alpha$-positive breast cancer because recent genome analyses have observed frequent activating PI3K mutation in ER $\alpha$-positive breast cancer, which often leads to increased AKT activity [26,27]. Using chromatin immunoprecipitation coupled microarray (ChIP-on-chip) and gene expression analysis, we demonstrated specific effects of AKT on ER $\alpha$ binding to the genome and E2regulated transcription [28]. The effect of AKT on E2induced alternative splicing is unknown. To test the effect of AKT on E2-induced alternative splicing, we first performed CD44 minigene splicing assay and observed a dominant effect of AKT on E2-induced alternative splicing in two cell types examined. To identify endogenous targets of E2-regulated alternative splicing and the influence of AKT on this process, we performed ExonHit Apoptosis Splice Array analysis of ER $\alpha$-positive/E2dependent MCF-7 breast cancer cells (MCF-7p) and the same cell line overexpressing constitutively active AKT (MCF-7AKT) with or without E2 treatment. Combined analysis of splice array and other published cancerspecific splicing data with E2-induced ER $\alpha$ cistrome and gene expression arrays revealed two distinct categories of E2-regulated alternatively spliced genes [17,28-30]. E2 induced alternative splicing of FAS/CD95 in MCF-7 cells, which correlated with resistance to FAS-activation induced apoptosis. In addition, E2 increased the expression of fibroblast growth factor receptor 2 (FGFR2) C1 isoform without significantly altering $\mathrm{C} 2$ isoform levels in MCF-7p cells. Consistent with the effect of E2 on FGFR2 splicing, MCF-7 cells showed differential response to keratinocyte growth factor (KGF), a ligand for FGFR2 $\mathrm{C} 1$ and $\mathrm{C} 2$ isoforms, in the presence of $\mathrm{E} 2$ and tamoxifen, an anti-estrogen. Furthermore, acquired resistance to anti-estrogens tamoxifen and fulvestrant was associated with distinct expression pattern of FGFR2 isoforms and response to KGF. Collectively, these results suggest a role for E2 induced alternative splicing in antiestrogen response of breast cancer cells.

\section{Results}

AKT influences E2 induced alternative splicing

Apart from SR proteins that are phosphorylated by AKT [11], the RS domain of splicing factors CAPER $\alpha$ and 
CAPER $\beta$ contain several putative AKT phosphorylation sites [23]. Both CAPER $\alpha$ and CAPER $\beta$ associate with $\mathrm{ER} \alpha$ and modulate E2-dependent transcription as well as alternative splicing [23]. Thus, AKT can potentially influence E2-induced alternative splicing by phosphorylating multiple components of the splicing machinery. We used the CD44 minigene splicing system containing variable exons 4 and $5(\mathrm{v} 4,5)$ of CD 44 gene under the control of estrogen response element driven promoter (ERE-CD44) and measured the exon inclusion/skipping to determine the effect of AKT on E2-induced alternative splicing [21]. Two cell systems were used: 1) 293 cells requiring transfection of both the CD44 minigene and ER $\alpha$ or its mutants; 2) MCF-7p and MCF-7AKT cells transfected with the CD44 minigene. Studies in 293 cells allowed us to study phosphorylation defective mutants of ER $\alpha$ on splicing as these cells lack ER $\alpha$. Studies in MCF-7 cells allowed us to study E2-induced splicing in the context of E2 responsive breast cancer cells, endogenous ER $\alpha$ and to distinguish ERE-dependent and ERE-independent effects of E2 on alternative splicing. We designed unique primers spanning exon-exon junctions to measure exon-included and exon-skipped products by quantitative reverse transcription polymerase chain reaction (qRT-PCR).

In 293 cells, only exon skipped transcripts from ERECD44 minigene could be reliably measured in the absence and presence of E2 by qRT-PCR (exon-included $\mathrm{CT}>30$, exon-skipped $\sim 25)$. In contrast, robust ERECD44 gene activity with expression of both exonincluded $(\sim 27 \mathrm{CT})$ and exon-skipped products $(\sim 24 \mathrm{CT})$ was observed when co-transfected with ER $\alpha$ (Figure 1A). The exon-inclusion/exon-skipped ratio changed dramatically in cells treated with E2 for 24 hours (range 1.7 to 6 fold in favor of included product, Figure 1A). We next compared E2-induced alternative splicing in the presence of MAPK-phosphorylation defective (S118A) and AKT phosphorylation defective (S167A) mutants of ER $\alpha$. $\mathrm{ER} \alpha$ mutants were effective as wild type ER $\alpha$ in modulating alternative splicing in the presence of E2 (Figure 1A).

We then compared ER $\alpha$ :E2-induced alternative splicing in the presence of constitutively active AKT. AKT had a dominant effect on alternative splicing of ERECD44 minigene-derived transcripts. Compared to control vector-transfected cells, exon-included/exon-skipped transcript ratio was dramatically lower indicating the ability of AKT to promote exon skipping and E2 failed to reverse this effect of AKT (Figure 1A, $\mathrm{p}=0.003$ ). Please note that AKT did not influence transcription of ERE-CD44 minigene in the absence of ER $\alpha$, as only exon-skipped transcripts under this transfection condition could be reliably measured (data not shown). Interestingly, AKT failed to influence alternative splicing events orchestrated by ER $\alpha$ phosphorylation defective

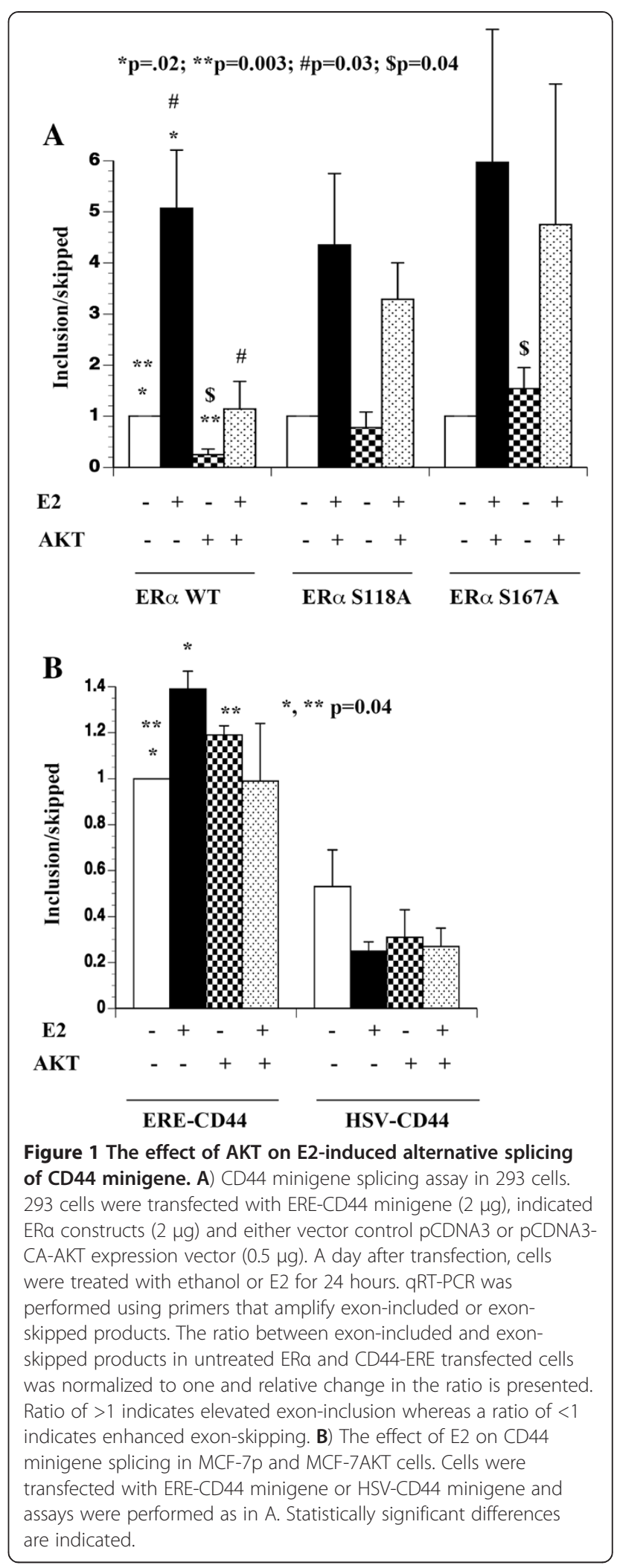


mutants. In particular, the ability of AKT to promote exon skipping was completely lost in cells transfected with S167 mutant, which is defective in AKT-mediated phosphorylation $(\mathrm{p}=0.04$; exon inc/skip ratio in wild type vs $\mathrm{S} 167 \mathrm{~A}$ mutant ER $\alpha$ transfected cells with AKT). These results indicate that AKT alters ER $\alpha: E 2$ induced alternative splicing in ER $\alpha$ S167 phosphorylationdependent manner to a larger extent and S118 to a minor extent.

We performed similar assay in parental MCF-7 cells (MCF-7p) and cells overexpressing AKT (MCF-7AKT) with ERE-CD44 minigene. Additionally, we included CD44 minigene driven by herpes simplex virus enhancer-promoter (HSV-CD44) to account for secondary effects of ER $\alpha$ :E2 on alternative splicing. As with 293 cells, E2 increased exon-inclusion/exon-skipped ratio in cells transfected with ERE-CD44 minigene (Figure 1B). Although alternative splicing of HSV-CD44 minigene in E2 treated cells was different from untreated cells, none of the differences reached statistical significance (Figure 1B). Similarly, AKT had minimum effect on alternative splicing of transcripts from HSV-CD44 minigene (Figure 1B). Taken together, these results suggest that E2 has distinct effects on alternative splicing of genes with ERE compared to genes without ERE. In addition, AKT has dominant effect on E2-induced alternative splicing or confers ligand-independent splicing activity to ER $\alpha$, depending on the cell type.

E2 induced alternative splicing of apoptosis-related genes To identify endogenous targets of E2-induced alternative splicing and the potential influence of AKT in this process, we performed microarray analysis that detects alternative splicing of 893 genes related to apoptosis. Array analysis was performed in quadruplicate using RNA from MCF-7p and MCF-7AKT cells with or without E2 treatment for three hours. Three hours time point was selected to enrich for genes that are primary targets of E2-regulated transcription and alternative splicing. Data from both cell types together with or without E2 treatment were analyzed using a more comprehensive ANOVA model after dye bias and cell type effects were removed. Four hundred sixty three splicing events out of possible 10659 splice events $(\mathrm{p}<0.001)(\sim 4 \%)$ targeting 154 genes (17\% of genes) were altered in E2 treated cells compared to untreated cells. These events were common to both cell types. Individual cell types also showed E2dependent changes in splicing patterns (527 in MCF-7p and 451 in MCF-7AKT) although statistical analysis is not as robust as combined analysis because comparison was only between two cell types (with and without E2 treatment). A gene list is provided as Additional file 1, Additional file 2, Additional file 3 available online and a partial list of the genes, few of which were verified further by qRT-PCR assays, is provided in Table 1 along with type of splicing events and fold change in response to E2 treatment.

\section{Genes that undergo E2-induced alternative splicing are enriched for ERa binding sites}

E2 induced alternative splicing could involve E2regulated transcription-coupled splicing, ER $\alpha$ binding to the gene that permits co-recruitment of splicing factors without an effect on the rate of transcription initiation, or a secondary event due to E2-mediated induction/repression of a splicing factor(s). To test these possibilities, we examined alternatively spliced genes for ER $\alpha$ binding sites from our previous ChIP-on-chip study datasets of MCF-7p and MCF-7AKT cells as well as a published study involving ChIP-seq of untreated, E2-treated or tamoxifen treated MCF-7 cells [28,29]. Among 154 genes that underwent alternative splicing in E2 treated cells, 89 genes contained ER $\alpha$ binding sites in regions within or $\sim 20-\mathrm{kb}$ $5^{\prime}$ or $3^{\prime}$ of the coding unit (Additional file 1). A 20-kb window has previously been shown to be optimal for ER $\alpha$ enhancer-promoter interactions [31]. However, we cannot rule out the possibility of ER $\alpha$ binding sites located at 50-100 KB distance from 5' and 3' of the coding units and ER $\alpha$ binding to these sites influencing gene expression or alternative splicing through looping mechanism. We had previously shown that 299 of 837 E2-regulated genes in MCF-7p cells and 363 of 1063 E2-regulated genes in MCF-7AKT cells ( 35\%) contain ER $\alpha$ binding sites [28]. In comparison, it appears that ER $\alpha$ binding sites are enriched on genes that underwent E2-induced alternative splicing ( 89 out of $154, \sim 60 \%, \mathrm{p}=0.0001$, Fisher's exact test).

ER $\alpha$ binding pattern to AXIN-1, Caspase 7, FGFR2, and FAS, which were alternatively spliced upon E2 treatment, is shown in Figure 2. FGFR2 displayed unique $\mathrm{ER} \alpha$ binding sites in cells overexpressing AKT and one of these sites is located in intron 2. This intron contains binding sites for several transcription factors and single nucleotide polymorphism in this intron is associated with breast cancer susceptibility, particularly postmenopausal breast cancers, which are usually ER $\alpha$-positive [32-34]. Although our ChIP-on-chip did not identify ER $\alpha$ binding sites around FAS, ChIP-seq data from the other study [29] showed an ER $\alpha$ binding site $\sim 40 \mathrm{~kb}$ upstream of the transcription start site. We performed ChIP assay with ER $\alpha$ antibody followed by qPCR to confirm ER $\alpha$ binding to select binding sites of the above genes (Figure 3A). Although assays were performed at three time points after E2 treatment (one, two, and four hours after E2 treatment), time points that showed significant ER $\alpha$ binding differences between untreated and E2 treated conditions are shown in the figure. With the exception of FAS, statistically significant increase in ER $\alpha$ 
Table 1 Selected E2-induced splicing events

\begin{tabular}{|c|c|c|c|c|c|c|}
\hline Gene name & Reference & Variant & $\begin{array}{l}\text { Splicing } \\
\text { event }\end{array}$ & $\begin{array}{l}\text { Long } \\
\text { form }\end{array}$ & $p$ value & $\begin{array}{l}\text { Fold change } \\
\text { with E2 }\end{array}$ \\
\hline \multirow{5}{*}{$\begin{array}{l}\text { Caspase 7, apoptosis-related cysteine protease (CASP7), } \\
\text { transcript variant beta, }\end{array}$} & \multirow[t]{5}{*}{ NM_033340 } & BM459840 & ASA & $\mathrm{R}$ & 0.000 & 2.01 \\
\hline & & BG339524 & ES & $\mathrm{R}$ & 0.000 & 2.20 \\
\hline & & BX458514 & ES & $\mathrm{R}$ & 0.000 & 1.96 \\
\hline & & AU131461 & ASD & $\mathrm{R}$ & 0.000 & 2.21 \\
\hline & & BX443602 & ASD & V & 0.000 & 2.18 \\
\hline \multirow[t]{2}{*}{ Axin 1 (AXIN1), transcript variant 1} & \multirow[t]{2}{*}{ NM_003502 } & AA954457 & ES & $\mathrm{R}$ & 0.000 & 1.48 \\
\hline & & BU500157 & ES & $\mathrm{R}$ & 0.000 & 1.48 \\
\hline \multirow[t]{3}{*}{ Cyclin E1 (CCNE1), transcript variant 1} & \multirow[t]{3}{*}{ NM_001238 } & BG395682 & ES & $\mathrm{R}$ & 0.000 & 1.41 \\
\hline & & CR601172 & $\mathbb{R}$ & V & 0.000 & 1.57 \\
\hline & & BE887210 & ES & $\mathrm{R}$ & 0.001 & 1.41 \\
\hline Homeodomain interacting protein kinase 2 (HIPK2) & NM_022740 & AF326592 & ASA & $\mathrm{R}$ & 0.000 & 1.36 \\
\hline $\begin{array}{l}\text { Tumor necrosis factor receptor superfamily, member 12A } \\
\text { (TNFRSF12A, FN14) }\end{array}$ & NM_016639 & BC064377 & ES & $\mathrm{R}$ & 0.000 & -1.4 \\
\hline $\begin{array}{l}\text { Tumor necrosis factor receptor superfamily, member 10A } \\
\text { (TNFRSF10A) }\end{array}$ & NM_003844 & Bl029612 & ASD & $\mathrm{R}$ & 0.001 & -2.01 \\
\hline \multirow{2}{*}{$\begin{array}{l}\text { Inhibitor of DNA binding 1, dominant negative helix-loop-helix } \\
\text { protein (ID1), transcript variant } 2\end{array}$} & \multirow[t]{2}{*}{ NM_181353 } & Al767705 & PIED & $\mathrm{R}$ & 0.000 & -2.52 \\
\hline & & BP261920 & PIED & $\mathrm{R}$ & 0.000 & -2.71 \\
\hline $\begin{array}{l}\text { Tumor necrosis factor receptor superfamily, member } 6 \text { (TNFRSF6), } \\
\text { transcript variant } 1 \text { (FAS) }\end{array}$ & NM_000043 & NM_152876 & ES & $\mathrm{R}$ & 0.000 & 1.14 \\
\hline $\begin{array}{l}\text { Tumor necrosis factor receptor superfamily, member } 6 \text { (TNFRSF6), } \\
\text { transcript variant } 1 \text { (FAS) }\end{array}$ & NM_000043 & NM_152874 & ES & $\mathrm{R}$ & 0.001 & -1.36 \\
\hline $\begin{array}{l}\text { Ubiquitin-activating enzyme E1C (UBA3 homolog, yeast) (UBE1C), } \\
\text { transcript variant } 1\end{array}$ & NM_003968 & AV716795 & ASA & $\mathrm{R}$ & 0.000 & 3.85 \\
\hline
\end{tabular}

Reference and variant transcripts with accession number in the array are shown. Longer version of the transcript in the array (reference or the variant) is also indicated. Positive number in fold change column indicates E2-induced splicing generating higher levels of the variant whereas negative number indicates repression of splicing event leading to generation of the variant. ASA, alternative splice acceptor; ASD; Alternative splice donor; ES, exon skipping; IR, intron retention; PEID, partial internal exon deletion. Additional splicing events including novel exons (NE) are in Additional file 1, Additional file 2 , Additional file 3.

binding to specific regions of the above genes upon E2 treatment was observed in MCF-7p, MCF-7AKT, or both cell types. E2 had distinct effect on ER $\alpha$ binding to FAS gene in MCF-7p and MCF-7AKT cells. Unliganded ER $\alpha$ bound to previously identified ChIP-seq region in FAS gene in MCF-7p cells, which was reduced upon E2 treatment. However, in MCF-7AKT cells, E2 increased ER $\alpha$ binding, which correlated with repression of E2regulated expression of total FAS transcripts in these cells (see below). ChIP with control IgG did not display any E2-dependent increase in amplification of ER $\alpha$ binding regions (data not shown). Taken together, the results presented above demonstrate a correlation between ER $\alpha$ binding to genes whose transcripts undergo alternative splicing in response to E2 treatment.

We used two resources to determine whether E2induced alternative splicing is coupled to ER $\alpha$ binding as well as changes in overall rate of transcription. First, we determined the effect of E2 on overall mRNA levels of alternatively spliced genes with $E R \alpha$ binding sites in MCF-7p or MCF-7AKT cells using gene expression array data from same cells treated with E2 for four hours [28].
Among 89 alternatively spliced genes with ER $\alpha$ binding sites, E2 induced the expression of eight genes but repressed the expression of two genes in MCF-7p cells. In MCF-7AKT cells, E2 increased the expression of 12 genes but repressed the expression of four genes (Additional file 1). Therefore, $\sim 80 \%$ of genes with ER $\alpha$ binding sites undergo alternative splicing upon E2 treatment without changing overall levels of transcription. The second set of data derived from the publicly available database (www.nursa.org/gems/) was used to independently verify this possibility. This database contains gene expression meta-signature of MCF-7 cells treated with E2 for three hours and 24 hours, which permitted us to measure early and late effects of E2 on overall transcription of alternatively spliced genes [30]. Among 89 genes with ER $\alpha$ binding sites, 18 genes were early-response inducible genes (3-4 hours) whereas 15 genes were late-response inducible genes (24 hours) with q-value of $<0.05$ (Additional file 1, Additional file 4). 16 and 22 genes were repressed at early and late time points, respectively. Remaining genes with ER $\alpha$ binding sites (60\%) underwent alternative splicing without an effect 

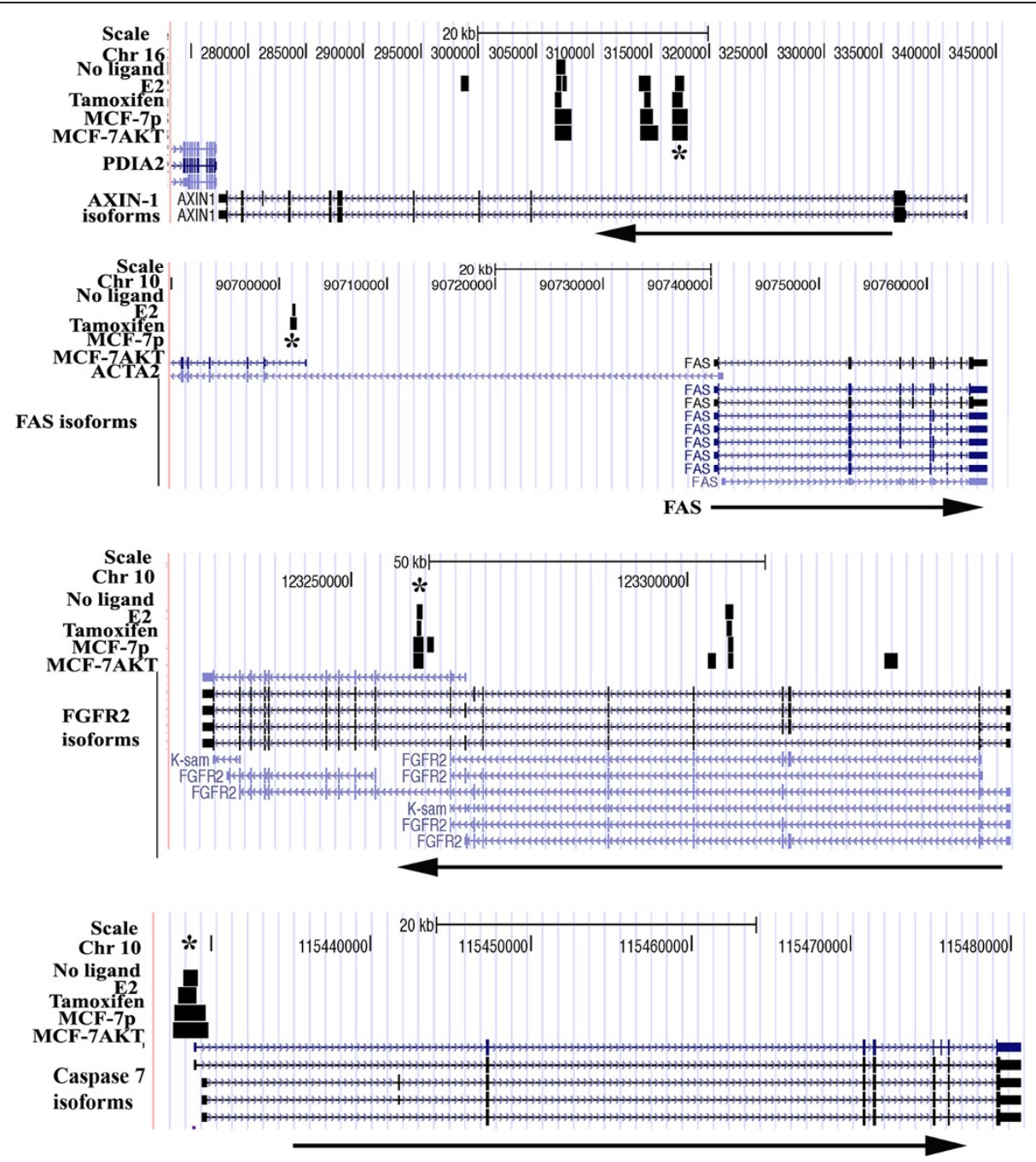

Figure 2 ERa binding pattern to alternatively spliced genes in response to E2 treatment. ChIP-on-chip data of MCF-7p and MCF-7AKT cells and/or ChIP-seq of MCF-7 cells with or without E2 or tamoxifen treatment reveal ERa binding sites within or around alternatively spliced genes. Relative position of genes on respective chromosomes along with ERa binding site detected in treated cells (black bar) are shown. Black arrow indicates direction of the gene. Asterisk indicates ERa binding sites verified by ChIP-qPCR.

on overall transcription after E2 treatment. Among 65 alternatively spliced genes without ER $\alpha$ binding sites, 13 and 19 genes were early and late E2 induced genes, respectively, whereas four and 10 were early and late repressed genes, respectively. Based on these two independent analyses, we conclude that E2 induced alternative splicing need not have to be coupled to the effects of E2 on the rate of transcription initiation. In fact, E2 had no effect on transcription of the majority of genes (85 out of 154 were unaffected at the level of transcripts) that underwent E2-regulated alternative splicing with or without ER $\alpha$ binding sites.

\section{E2 regulated expression of splicing factors}

Since $\sim 40 \%$ of genes lacking ER $\alpha$ binding sites within $20 \mathrm{~kb}$ of 5' and 3' ends of the coding unit underwent E2 dependent alternative splicing, we examined the effect of E2 on the expression of genes of the alternative splicing machinery including those linked to cancer. First, we analyzed ChIP-on-chip for ER $\alpha$ binding and gene expression array data of E2 treated MCF-7p and MCF-7AKT cells for E2-regulated expression of splicing factors [28] and observed E2-dependent increase in the SRSF7 (also called 9G8) by more than 2-fold. Indeed, E2 increased the expression of SRSF7 in both MCF-7p and MCF7AKT cells by more than 2-fold, despite lacking ER $\alpha$ binding sites based on ChIP-on-Chip and ChIP-seq data (Figure 3B). Therefore, SRSF7 may contribute to E2regulated alternative splicing of genes without ER $\alpha$ binding sites. FOX2 (also called RBM9) downregulation is responsible for cancer-associated alternative splicing [16]. However, FOX2 gene lacks ER $\alpha$ binding sites and 


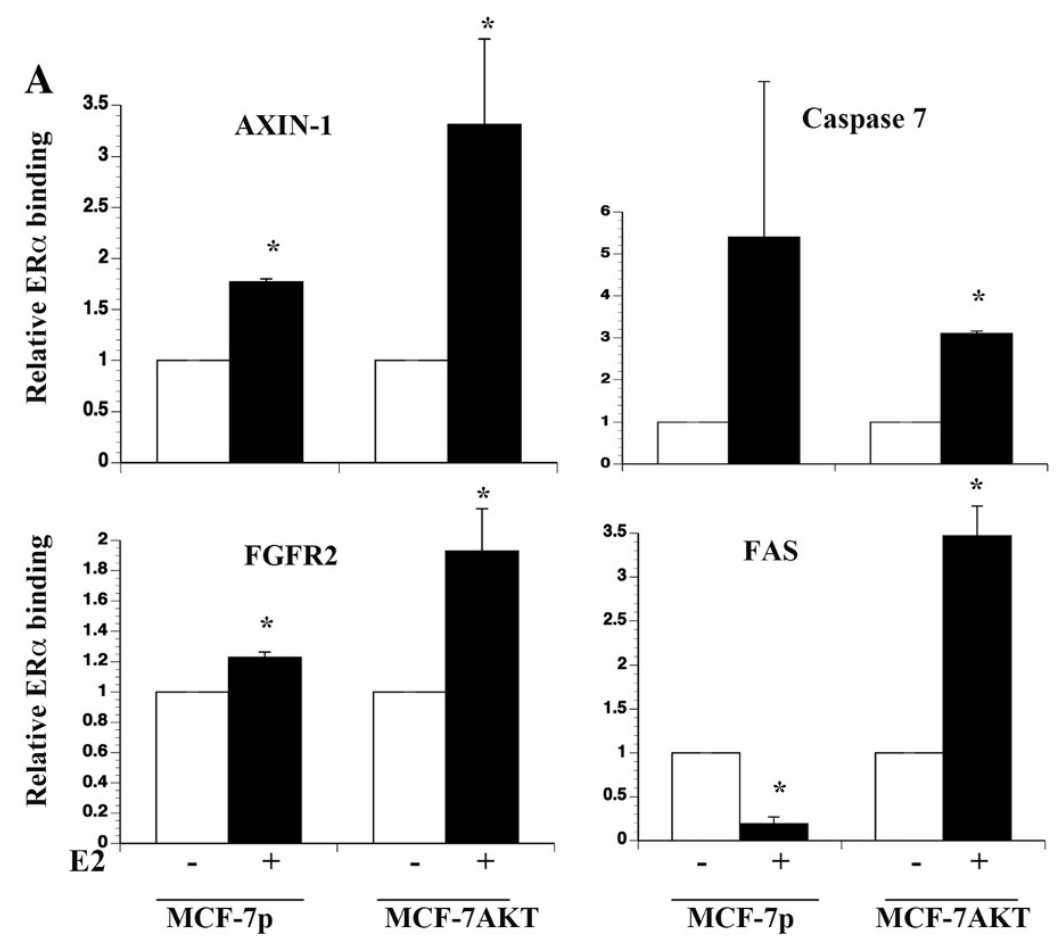

B

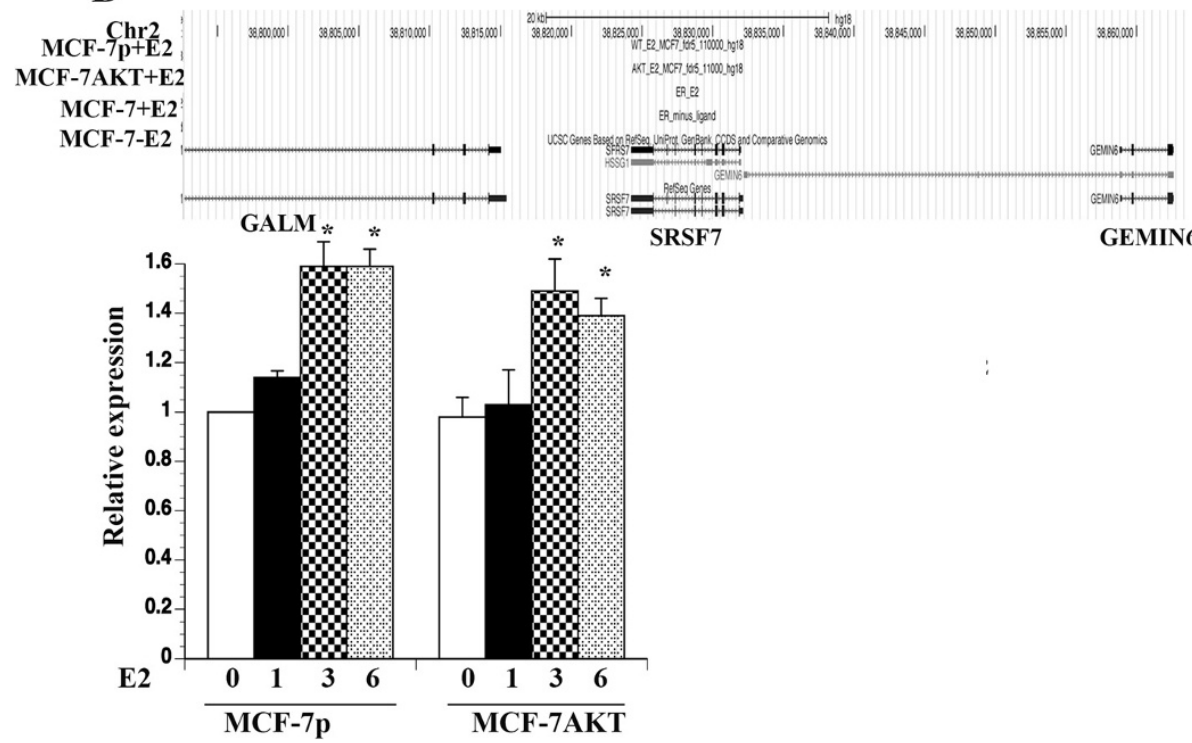

Figure 3 Verification of ER $a$ binding to alternatively spliced genes. A) ChIP-qPCR was used to confirm ERa binding to genomic regions of AXIN-1, Caspase 7, FGFR2, and FAS genes. Relative enrichment of ERa binding upon E2 treatment is shown (average and standard error of the mean). Data from one hour (AXIN-1 and FGFR2), two hours (Caspase 7), and four hours (FAS) after E2 treatment are shown. Asterisks indicate significant enrichment or loss of binding $(p<0.02)$ upon E2 treatment. B) E2 increases SRSF7 expression in both MCF-7p and MCF-7AKT cells. Mean \pm SE is shown. ${ }^{*} p<0.05$, untreated versus E2 treated. The chromosomal region encompassing SRSF7 gene lacks ERa binding sites based on our ChiP-on-chip as well as ChIP-seq data published by others (top).

E2 had no effect on its expression in MCF-7p and MCF7AKT cells [28]. Genome-wide RNAi screen for genes involved in alternative splicing of apoptosis-related genes revealed ASF/SF2/SRSF1 as the main splicing factor that regulates apoptosis [35]. The regulatory regions of SF2 contain an ER $\alpha$ binding site; however, E2 did not alter the expression of this gene in both MCF-7p and MCF7AKT cells. The regulatory regions of Polypyrimidine Tract Binding protein 1 (PTB), another cancer-associated splicing factor [13], bind to ER $\alpha$ in tamoxifen but not E2 
treated cells and E2 induces its expression only after 24 hours. Thus, PTB is less likely to be a major player in E2-induced alternative splicing. The regulatory regions of SRp20, another splicing factor overexpressed in cancer [36], contain ER $\alpha$ binding sites and SRp20 is induced by E2 at transcript level (1.36-fold, q value $<0.01)$. However, we did not observe elevated SRp20 protein levels in cells treated with E2 compared to untreated cells possibly due to higher abundance and stability of the protein (data not shown). Furthermore, analysis of more than 20 known splicing factors did not reveal significant effects of E2 on their expression [37,38]. Thus, SRSF7 is the only documented E2-inducible splicing factor, which may cause alternative splicing as a secondary event in E2 treated cells.

\section{Characterization of E2-induced alternative splicing at mRNA level}

A schematic view of some of the genes that underwent alternative splicing in response to E2 treatment is given in Figure 4A. Alternative splicing pattern of the FGFR2 C-terminus is also shown. FGFR2 was included in this analysis because it is one among 19 genes that undergo breast cancer-specific alternative splicing, which results in proteins with distinct functional domains [17]. To visualize and measure splice variants, we employed qRTPCR using primer sets that measure wild type or isoform mRNA levels. We selected AXIN-1, FAS, and FGFR2 for further analysis because of their known role in breast cancer and apoptosis.

AXIN-1a and AXIN-1b showed distinct expression pattern in MCF-7p and MCF-7AKT cells. In MCF-7p cells, E2 increased the expression of both AXIN-1a and AXIN-1b although there was a difference in the expression levels of these isoforms at given time after E2 treatment (Figure 4B). Basal AXIN-1a but not AXIN-1b levels were lower in MCF-7AKT cells compared to MCF-7p cells $(p=0.006)$ suggesting the ability of AKT to alter AXIN-1 splicing independent of ER $\alpha$ and E2. Consequently, overall levels of AXIN-1a but not AXIN-1b were lower in E2 treated MCF-7AKT cells compared to MCF-7p cells. AXIN-1b lacks exon-8, which codes for a 30 amino acid region containing a putative casein kinase I phosphorylation site, oligomerization site, and two potential nuclear export signals [39].

Several isoforms of FAS have been characterized [40]. FAS lacking exon 6, which is a more frequent event in cancer, yields a soluble FAS protein with anti-apoptotic activity $[13,40]$. ExonHit array experiments identified E2-inducible expression of an isoform lacking exons 3, 4, and 6 (NM_152876) but repression of another isoform lacking both exons 4 and 7 (NM_152874) in MCF-7p cells (Table 1 and Additional file 2). We designed multiple qRT-PCR primers to measure the levels of total
FAS transcripts (primers spanning exon 9) and splice variants alone. Only primers spanning total FAS and the splice variant lacking exons 3 and 4 (forward primer designed to exon 2 and 5 junction and reverse primer spanning exon 6) gave reproducible results. E2 did not change the levels of total FAS transcripts but significantly increased the levels of the splice variant lacking exons 3 and 4 in MCF-7p cells (Figure 4C) (please see Figure 5 below for even higher induction of the splice variant). E2 decreased the levels of full length but not the splice variant in MCF-7AKT cells after one-hour treatment suggesting a dominant effect of AKT in redirecting ER $\alpha$ to suppress total FAS.

Alternative splicing of FGFR2 generates epithelial cell specific FGFR2 IIIb and mesenchymal cell specific FGFR2 IIIc isoforms [32]. Overall, alternative splicing generates at least 11 splice variants of FGFR2. The Cterminus of FGFR2 IIIb undergoes further alternative splicing to generate constitutively active (C3) and ligand-dependent $(\mathrm{C} 1$ and $\mathrm{C} 2$ ) receptors [41-43]. We generated primers that can specifically measure the levels of $\mathrm{C} 1+\mathrm{C} 2, \mathrm{C} 2$, or $\mathrm{C} 3$ transcripts by qRT-PCR and determined the effect of E2 on expression levels of each isoforms in MCF-7p and MCF-7AKT cells. Based on the $\mathrm{CT}$ values, $\mathrm{C} 1+\mathrm{C} 2$ transcript is the predominant FGFR2 ( 20 CT value) compared to $\mathrm{C} 2(\sim 26 \mathrm{CT}$ value) or C3 $(\sim 29 \mathrm{CT}$ value $)$ in both cell types. RT-PCR assay also confirmed relative abundance of $\mathrm{C} 1$ and $\mathrm{C} 2$ transcripts compared to $\mathrm{C} 3$ transcripts (data not shown). In MCF$7 \mathrm{p}$ cells, $\mathrm{E} 2$ increased $\mathrm{C} 1+\mathrm{C} 2$ but not $\mathrm{C} 2$ transcript to a significant level $(p=0.0001$, Figure $4 D)$. In contrast, C3 levels were significantly reduced in MCF-7p cells treated with E2 for one hour ( $p=0.004)$. C1 levels remain significantly higher compared to C3 levels after three hours of $\mathrm{E} 2$ treatment $(\mathrm{p}=0.0089)$. The basal $\mathrm{C} 1+\mathrm{C} 2$ was higher in MCF-7AKT cells compared to MCF-7p cells $(\mathrm{p}=0.05)$, while the levels of $\mathrm{C} 2$ were similar in MCF-7p and MCF-7AKT cells (Figure 4D). In addition, E2 failed to repress C3 levels in MCF-7AKT cells. These effects of AKT on E2-induced splicing of endogenous genes are consistent with the results obtained in transient assays with ERE-CD44 minigene where AKT overexpression recapitulated some of the splicing events that occur in E2 treated cells (Figure 1B). Since AKT decreased the level of specific splice variant in some cases (AXIN-1a for example) but increased splice variants in other instances (FGFR $\mathrm{C} 1+\mathrm{C} 2$, for example), the effects of $\mathrm{AKT}$ on alternative splicing of E2-regulated genes is genespecific but not global. We emphasize that the extent of E2- or AKT-mediated changes in alternative splicing of endogenous genes shown above (30 to $70 \%$ ) is similar to changes in alternative splicing observed during important biological processes such as embryonic stem cell differentiation ( $<36 \%$ change in FOXP1 alternative splicing) [15]. 


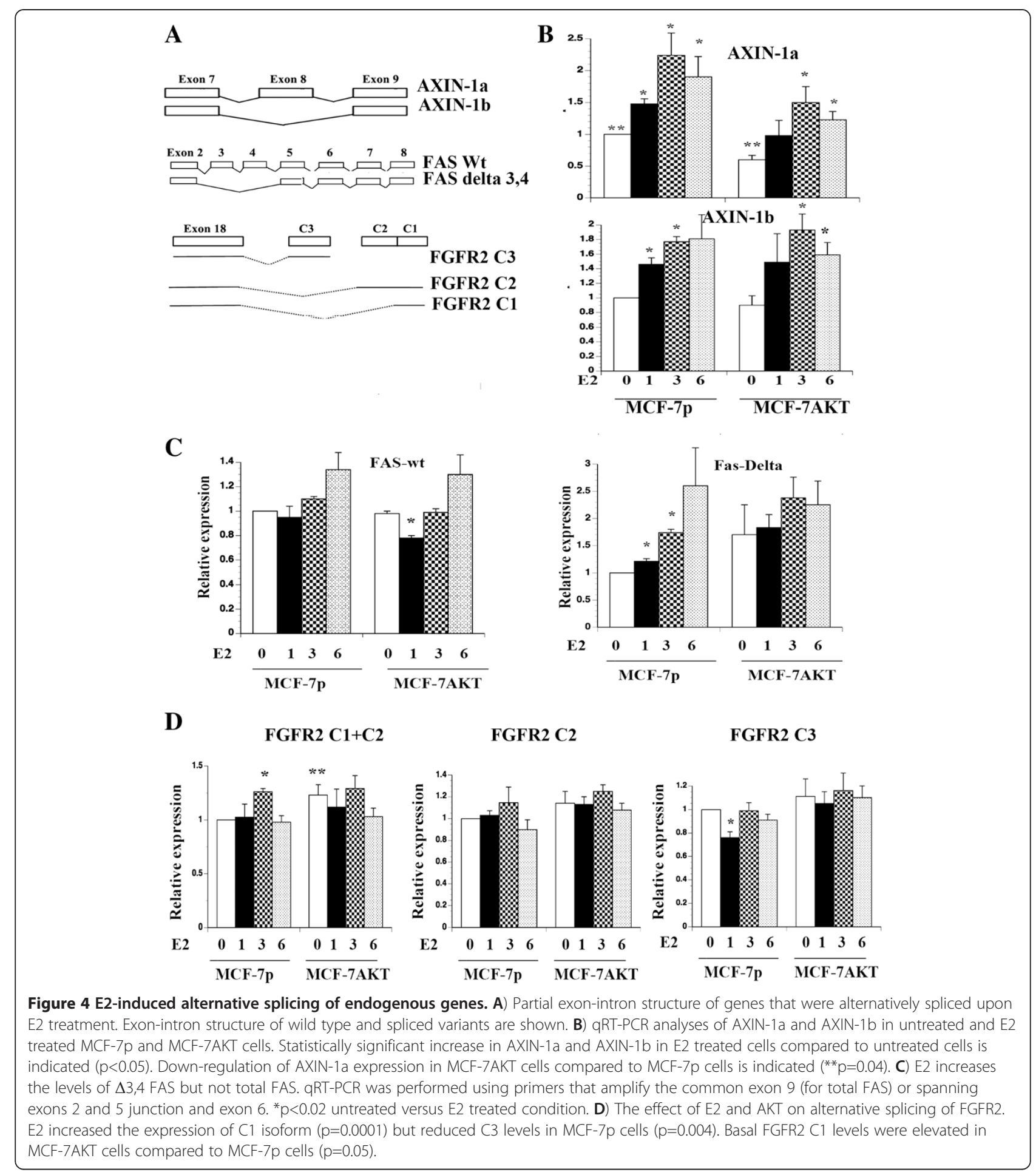

The effect of E2 on FAS and FGFR2 proteins

To further confirm E2-induced alternative splicing of above genes leads to measurable expression of distinct protein species, we performed western blotting. These studies were not intended to show a direct correlation between alternatively spliced mRNA and translation of the specific spliced mRNA into a protein. Instead, the purpose was to show that the alternative splicing creates translatable mRNAs. Indeed, E2 treated cells showed a faster migrating FAS protein of $\sim 38 \mathrm{kDa}$ in MCF-7p cells and the basal level of this faster migrating protein was constantly higher in MCF-7AKT cells (Figure 5A). We do note that there were experimental variations in the number of faster migrating bands of FAS in E2 
treated cells as well as detection by Western blot analysis possibly reflecting experimental and/or cell lysis conditions altering the stability of the isoforms (data not shown). In addition, since FAS undergoes multiple alternative splicing [40], it is impossible to assign a splice variant transcript to a protein species.

We further characterized the role of AKT in E2induced alternative splicing of FAS by generating MCF-7 cells overexpressing dominant negative AKT (KD-AKT) [6]. While E2 increased alternatively spliced FAS in parental cells, this effect of E2 was completely abolished in cells overexpressing KD-AKT (Figure 5B).
We observed an effect of E2 on two FGFR2 protein species in MCF-7p cells (Figure $5 \mathrm{C}$ ). One is an abundantly expressed faster migrating protein, which was induced by E2 (indicated by an arrow). The basal level of this FGFR2 protein was significantly higher in MCF7AKT cells compared to MCF-7p cells. Another minor slower migrating FGFR2 protein was detected in both cells and levels of this protein declined initially with E2 treatment but restored/increased after 24 hours (indicated by an arrow with star). To determine the requirement of ER $\alpha$ for the expression of these isoforms of FGFR2, we knocked down ER $\alpha$ using siRNA. ER $\alpha$ siRNA 
significantly reduced basal and E2-inducible expression of both FGFR2 protein species in MCF-7AKT cells (Figure 5D). We are unsure why ER $\alpha$ siRNA had lower effect on FGFR2 expression in MCF-7p cells. Residual ER $\alpha$ in siRNA treated cells may be sufficient for FGFR2 expression in these cells.

\section{Anti-estrogen resistance is associated with differential FGFR2 C isoform expression}

We next investigated whether resistance to antiestrogens is associated with altered expression of FGFR2 isoforms. For this purpose, we used a single cell-derived clone of MCF-7 cell line that has acquired resistance to tamoxifen (OHTR) or fulvestrant (Ful-R). MCF-7 and OHTR cells express similar levels of ER $\alpha$, whereas Ful-R cells express very little ER $\alpha$ protein compared to other cell types [44]. Western blot analysis was performed to determine whether FGFR2 isoforms are differentially expressed in these cell lines. Similar to results presented in Figure 5, two FGFR2 proteins, one abundant faster migrating species and one minor slower migrating species were detected in these cell lines and E2-dependency varied between cell lines (Figure 6A). The basal expression of the faster migrating band was significantly higher in OHTR cells compared to parental cells and was not influenced by E2 in this cell line. Note that OHTR cells do not express slower migrating FGFR2 indicating isoform switching in resistant cells. In contrast, the minor slower migrating FGFR2 was E2-inducible in the parental cell line but constitutively elevated in Ful-R cells. Therefore, anti-estrogen resistance is associated with alternative splicing of FGFR2 and corresponding change in protein levels. We used siRNA against ER $\alpha$ to determine which among the FGFR2 isoform expression requires ER $\alpha$. ER $\alpha$ siRNA completely abolished the E2inducible expression of slower migrating minor FGFR2 in parental cells and even in Ful-R cells, which has lower levels of ER $\alpha$ compared to other cell lines (Figure 6B). Therefore, elevated basal expression of slower migrating FGFR2 in Ful-R cells is dependent on residual ER $\alpha$ levels. Basal expression of faster migrating FGFR2 in OHTR cells was also ER $\alpha$ dependent. For unknown reason, we were only able to knockdown $<50 \%$ of ER $\alpha$ in this single cell-derived MCF-7 clone and OHTR cells. Despite discrepancy with respect to ER $\alpha$ dependency of faster migrating FGFR2 in parental MCF-7 cells and clonal MCF-7 (Figure 5 and Figure 6), results support the conclusion that slower migrating FGFR2 is E2 and/ or ER $\alpha$ dependent across cell lines.

To confirm that overexpression of FGFR2 protein in OHTR cells and lower expression in Ful-R cells correlate with mRNA changes, we performed qRT-PCR analysis (Figure 6C). OHTR cells expressed higher levels of all three FGFR2 isoforms tested, whereas Ful- $R$ cells expressed lower levels of all three isoforms tested compared to parental cells. Therefore, FGFR2 protein changes in antiestrogen resistant cells correlate changes in mRNAs but it is difficult to assign these changes to specific isoforms.

KGF serves as a ligand to FGFR2 C1 and C2 isoforms, whereas C3 is active independent of ligand [41,42]. Since OHTR cells expressed higher levels of FGFR2 protein compared to parental cells and Flu-R cells expressed different levels of FGFR2 isoforms compared to parental or OHTR cells, it is possible that anti-estrogen resistant cells respond differently to KGF compared to parental cells. While KGF stimulated the growth of parental cells, OHTR cells displayed elevated basal proliferation, which was unaffected upon KGF stimulation. Ful-R cells also displayed elevated basal proliferation and were unresponsive to KGF stimulation (Figure 6D). These results indicate that resistance to anti-estrogens is associated with differential FGFR2 isoform expression and response to KGF.

\section{FGFR2 C2 and FGFR2 C3 alter basal proliferation rate and consequently response to E2}

Since FGFR2 C2 isoform expression was not E2 responsive, whereas C3 expression was repressed by E2, we examined how constitutive overexpression of these isoforms alters cellular response to E2 and tamoxifen. Expression levels of overexpressed FGFR2 isoforms are shown in Figure 6E. Both FGFR2 C2 and C3 overexpressing cells showed elevated basal proliferation compared to parental cells with retrovirus vector alone and E2 further stimulated proliferation (Figure 6F). Similar to parental cells, tamoxifen reduced E2-stimulated proliferation of FGFR2 C2 and C3 overexpressing cells. These results suggest that FGFR2 C2 and C3 overexpression provides proliferative advantage mimicking increased proliferation observed with anti-estrogen resistant cells compared to parental cells. Overall, proliferation rate of $\mathrm{C} 2$ or $\mathrm{C} 3$ overexpressing cells was much higher than parental cells $(\mathrm{p}<0.0002)$. Proliferation rate of FGFR2 C2 overexpressing cells remained higher than parental cells when cells were treated with E2 plus tamoxifen. Thus, individual isoforms of FGFR2 can influence basal proliferation and consequently response to E2 and anti-estrogens. Since it is difficult to knockdown individual isoforms of FGFR2 due to limited sequence divergence between isoforms and to develop isoform specific inhibitors, our observation linking specific isoforms of FGFR2 to anti-estrogen response remains correlative.

Estrogen-induced alternative splicing of FAS and FGFR2 correlates with resistance to FAS activation-induced cell death and KGF-induced proliferation, respectively

To determine the consequences of E2-induced alternative splicing of FAS on sensitivity to FAS activation- 
$\mathbf{A}$

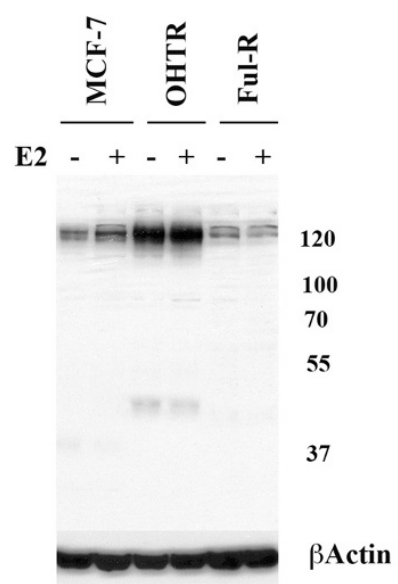

\section{B}

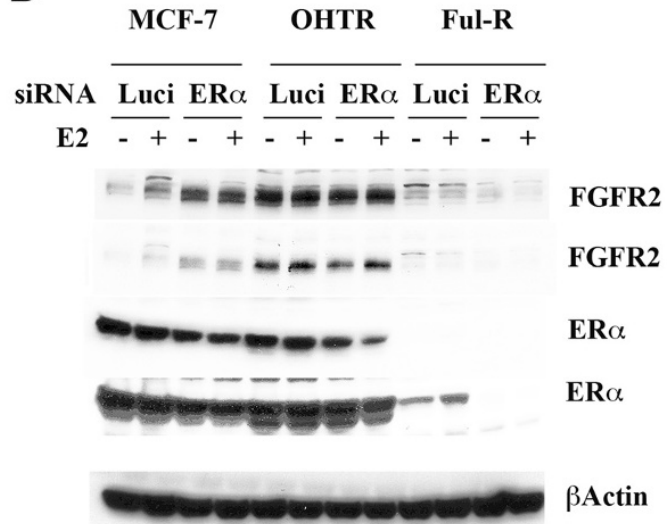

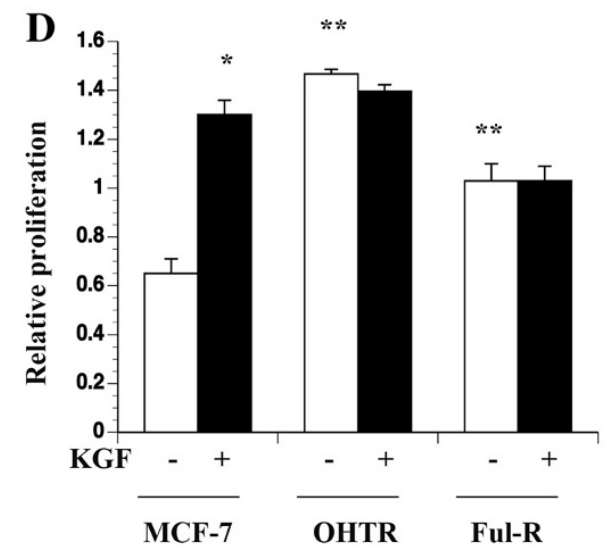

$\mathbf{E}$

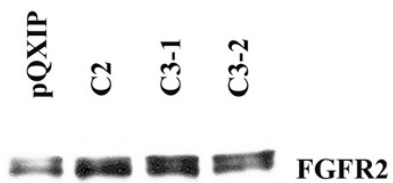

BActin
F

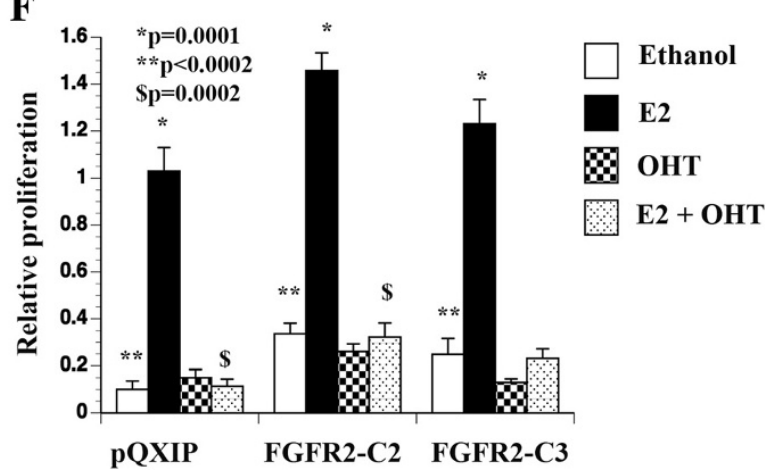

Figure 6 FGFR2 isoforms and anti-estrogen resistance. A) FGFR2 proteins in untreated and E2 treated (24 hours) MCF-7, OHTR, and Ful-R cells. Three cell types express different levels of FGFR2 proteins. B) FGFR2 C1, C2, and C3 mRNA levels in MCF-7, OHTR, and Ful-R cells. *,** p<0.05 compared to parental MCF-7 cells. C) ERa is essential for the expression of slower migrating FGFR2 protein. siRNA experiments were performed as in Figure 5. Two exposures of ERa blot are shown to demonstrate the presence of residual ERa in Flu-R cells. D) The effect of KGF on proliferation of MCF-7, OHTR, and Ful-R cells. Cells were treated with KGF for six days and cell proliferation was measured using BrDU-ELISA. KGF stimulated proliferation of MCF-7 cells but not OHTR or Ful-R cells ( ${ }^{*} p=0.0001$ ). OHTR and Ful-R cells displayed elevated basal proliferation compared to MCF-7 cells $\left({ }^{* *} \mathrm{p}=0.0001\right)$. E) Western blot analysis shows FGFR2 expression in vector control or FGFR2 C2 or C3 infected cells. F) E2 and tamoxifen sensitivity of FGFR2 C2 and C3 overexpressing cells. Cells were treated with E2 $\left(10^{-10} \mathrm{M}\right)$, 4-hydoxy tamoxifen $(1 \mu \mathrm{M})$ or both for six days and cell proliferation was measured using BrDU-ELISA. Basal proliferation of FGFR2 C2 and C3 overexpressing cells was significantly higher compared to parental cells. E2 stimulated proliferation of all three-cell types. 
induced cell death, we treated MCF-7p and MCF-7AKT cells with an antibody that triggers FAS-dependent apoptosis. MCF-7p and MCF-7AKT cells maintained in charcoal-stripped serum containing media displayed basal apoptosis, which was reduced upon E2-treatment (Figure 7A). FAS antibody treatment increased apoptosis in both cell types, which was more pronounced in MCF$7 p$ compared to MCF-7AKT cells. Lower sensitivity of MCF-7AKT cells compared to MCF-7p cells is consistent with diminished basal full-length FAS protein levels in these cells. This observation is also consistent with the known anti-apoptotic function of AKT [45]. E2 substantially reduced the FAS-antibody triggered apoptosis in both cell types. Thus, E2-induced alternative splicing of FAS may have an impact on FAS-activation mediated cell death.

We next examined the effect of KGF on growth of MCF-7p and MCF-7AKT cells in the presence of E2, low dose 4-hydroxy-tamoxifen, or both. (Figure 7B). At this dose, tamoxifen reduced only E2-induced growth of both cell types. KGF increased the proliferation of both cell types (untreated versus KGF treated $\mathrm{p}=0.006$ for

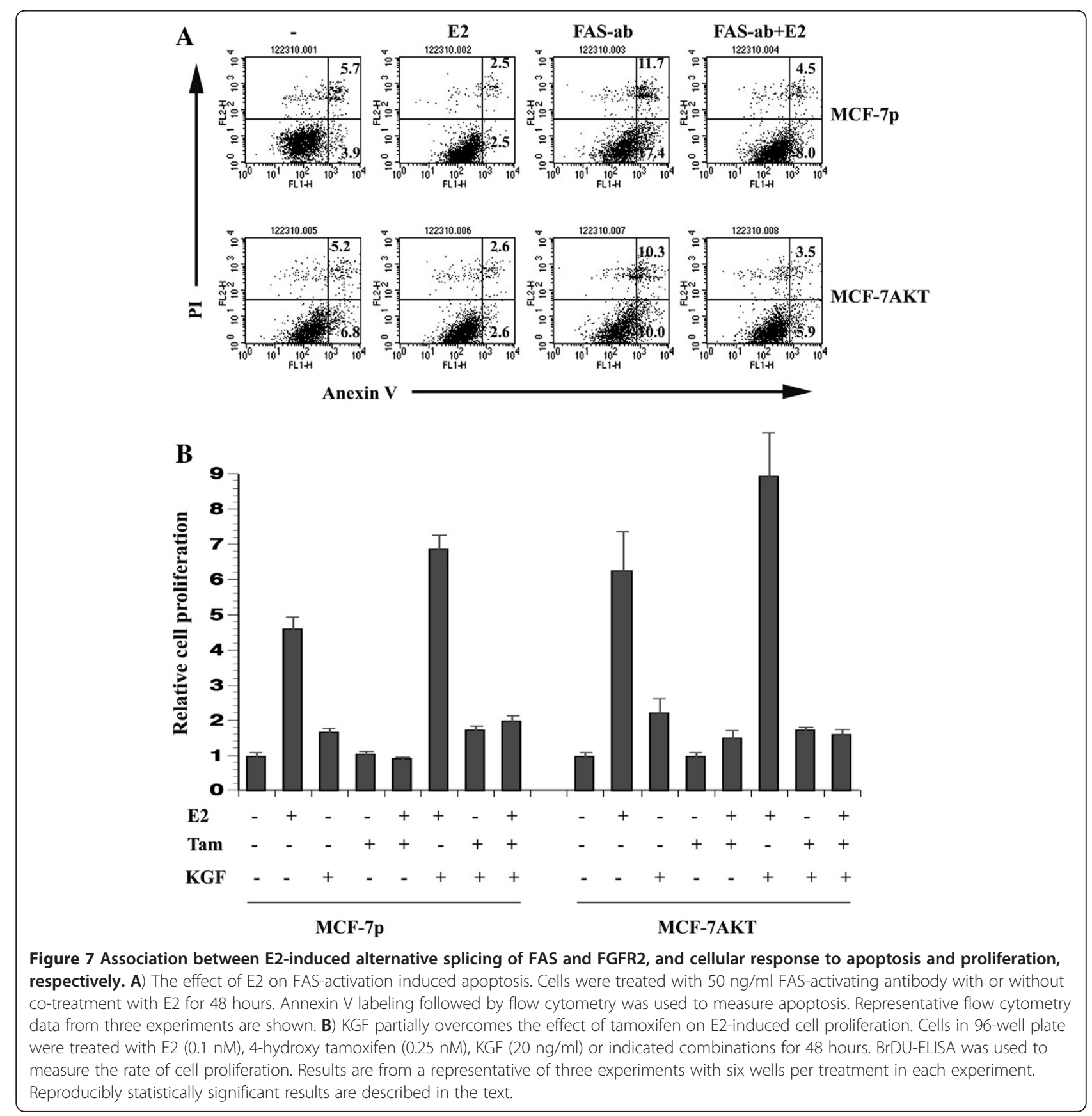


MCF-7p and 0.0127 for MCF-7AKT). KGF plus E2 treated MCF-7p cells but not MCF-7AKT cells showed significant increase in proliferation (MCF-7p cells E2 versus $E 2$ plus $K G F, p=0.015)$. The proliferation rate of MCF-7p cells treated with a combination of KGF, E2, and tamoxifen were higher than untreated, tamoxifentreated, and tamoxifen plus E2 treated cells $(\mathrm{p}<0.0002)$, indicating the ability of activated FGFR2 to overcome the effects of tamoxifen on E2-induced proliferation. Consistent with our previous results [6], MCF-7AKT cells treated with E2 plus tamoxifen were more proliferative than MCF-7p cells treated with E2 plus tamoxifen $(\mathrm{p}=0.021)$ and KGF did not additionally increase the proliferation of E2 plus tamoxifen treated MCF-7AKT cells. These results indicate E2-mediated increase in FGFR2 C1 isoform provides additional receptors for KGF allowing higher proliferation rate as well as diminished response to tamoxifen.

\section{Discussion}

\section{Role and regulation of ERa in E2-regulated alternative} splicing

Extracellular signal-dependent alternative splicing is a major mechanism responsible for diversification of molecular repertoire by affecting several cellular functions including apoptosis, stem cell maintenance and differentiation, cell migration, and invasion $[9,46,47]$. Apart from growth factor-induced signaling pathways, which can modulate alternative splicing through phosphorylation of splicing factors, steroid hormones couple transcription to splicing by recruiting splicing factors to the transcription machinery through nuclear receptors [21]. It is not known whether steroid hormones increase splicing efficiency without altering the rate of transcription. Genome wide analysis of ER $\alpha$ binding patterns has revealed that the largest fraction (38\%) of ER $\alpha$ binding sites is mapped to intragenic regions including introns and several of these interactions have previously been described as unproductive [48-50]. It is possible that the primary function of $E R \alpha$ bound to intragenic regions is to recruit splicing factors to modulate alternative splicing without changing overall transcription rates. ER $\alpha$ and associated co-factors recruited to these sites may induce specific histone modifications that favor exon skipping or exon inclusion [51].

It is interesting that several of the genes that underwent E2-regulated alternative splicing have intragenic ER $\alpha$ binding sites (Figure 2). In fact, $\sim 60 \%$ of the genes that bound to ER $\alpha$ and underwent alternative splicing without change in the rate of transcription (Additional file 1 and Additional file 4) may utilize ER $\alpha$ for local recruitment of histone modifying enzymes that favor alternative splicing events. We also observed both E2induced and repressed genes undergoing alternative splicing. Thus, E2-induced alternative splicing is unrelated to rate of transcription but could be related to the ability of E2:ER $\alpha$ to recruit histone-modifying enzymes along the path of transcript elongation. In this context, rate of transcription elongation has greater influence on alternative splicing [51]. Alternatively, E2 inducible splicing factors such as SRSF7 is responsible for E2-induced alternative splicing without an effect of E2 on rate of transcription. SRSF7 has previously been shown to increase alternative splicing of exon 6 of BRCA1 variant with exon skipping mutation c.231G>T [52]. Therefore, genetic variation, in addition to SRSF7 induction, may contribute to diversity in E2-regulated alternative splicing events.

A large number of splicing factors associate with ER $\alpha$ including splicing factors of the hnRNPA1 complex (CoAA for example) and SR proteins (CAPER and SF2) $[22,23,53]$. Select RNA-recognition motifs (RRMs) present in these splicing factors are involved in interaction with ER $\alpha$, transactivation, and splicing [53,54]. RS domains, which are present in SR proteins including SRSF7, are heavily phosphorylated by AKT [11]. Our results suggest that AKT has dominant but gene-specific effect on E2-induced alternative splicing. Activating mutation of AKT is mostly observed in ER $\alpha$-positive breast cancer [26]. Therefore, it is possible that the dominant gene-specific effect of AKT on ER $\alpha$ :E2 induced alternative splicing is one of many functions of AKT that contribute to tumorigenesis. However, mechanistic aspect of ER $\alpha$ :E2 induced alternative splicing, which is additionally controlled by AKT, remain to be investigated.

\section{E2-regulated alternative splicing and cell signaling}

To date, the specific contribution of ER $\alpha$ :E2-induced, repressed, and -alternatively spliced genes on breast tumorigenesis has not been established. However, our analyses show that ER $\alpha$ :E2 contributes to breast cancerenriched alternative splicing. Cancer cells often use alternative splicing as a mechanism to produce proteins that promote growth and survival [13]. Genes that we have characterized in this study for E2-regulated alternative splicing provide glimpse of how these alternativespliced products may alter signal transduction as well as response to therapy (Figures 6 and 7).

FGFR2 alternative splicing is highly relevant as polymorphism in intron 2, which may lead to increased expression, is associated with higher risk of breast cancer $[32,33]$. In this context, we observed overexpression of FGFR2 in tamoxifen-resistant cells. FGFR2 C1 and C2 isoforms are ligand dependent receptors that bind to $\mathrm{KGF}$, whereas the C3 isoform is constitutively active [42]. C1 isoform is expressed in normal mammary epithelial cells, whereas C3 expression is restricted to transformed cells [42]. Although all three isoforms have 
the transforming ability, C3 isoform is the most potent and imparts invasive capabilities [41,55]. Our results showed that E2 increases the expression of $\mathrm{C} 1$ isoform but reduces $\mathrm{C} 3$ expression in parental cells. AKT increased $\mathrm{C} 1$ in ER $\alpha$-dependent but E2-independent manner as siRNA against ER $\alpha$ reduced FGFR2 levels at both basal and E2 treated condition (Figure 5). FGFR2 overexpression and isoform switching are involved in anti-estrogen resistance as FGFR2 protein species in tamoxifen and fulvestrant resistant cells are different from each other as well as from parental cells. At present, there are no assays or reagents to verify whether FGFR2 proteins differentially expressed in anti-estrogen resistant cells correspond to $\mathrm{C} 1, \mathrm{C} 2$, or $\mathrm{C} 3$ isoforms characterized in this study. Presence of at least 11 different FGFR2 isoforms, most affecting open reading frames, complicates interpretation. Nonetheless, data presented in this study suggest FGFR2 is a target for overcoming anti-estrogen resistance in breast cancer. FGFRs (both 1 and 2) are upregulated in breast cancer and cooperate with Wnt signaling to enhance mammary tumorigenesis [56]. Whether E2-induced splicing of FGFR2 and AXIN-1 (a negative regulator of Wnt) contributes to this cooperative tumorigenesis and how aberrant splicing events contribute to response to therapy remains to be investigated.

Alternative splicing of FAS is linked to apoptosis resistance in cancer [40]. FAS itself regulates alternative splicing through dephosphorylation of SR proteins [57]. FAS-activated signaling is essential for bone protective function of E2 as it is responsible for E2-induced apoptosis of osteoclasts [58,59]. Paradoxically, FAS is essential in tumor growth, although whether this function of FAS is dependent on a particular isoform is unknown [60]. The effect of E2 in preventing FAS-activation dependent apoptosis in breast cancer cells will have an impact on therapeutic response as active Fas/FasL can amplify the pro-apoptotic effects of chemotherapeutic drugs.

\section{Conclusions}

This study identified E2 regulated alternative splicing of genes involved in apoptosis and breast epithelial cell transformation. E2-regulated splicing may be coupled to ER $\alpha$ :E2 regulated transcription or independent of transcription but involves ER $\alpha$ :E2 mediated recruitment of splicing factors/histone-modifying enzymes and/or E2 regulated expression of splicing factors such as SRSF7. Extracellular signal activated kinases such as AKT, which are often activated/overexpressed in therapy resistant breast cancers, may additionally alter these functions of E2 to modify the course of the disease. Furthermore, FGFR2 overexpression and/or alternative splicing may be associated with anti-estrogen resistance.

\section{Methods}

Plasmid constructs, reagents, and antibodies

CD44 minigene constructs have been described previously [21]. The constitutively active AKT (CA-AKT) and the dominant negative AKT (KD-AKT) have been described previously [6] and retrovirus constructs with $\mathrm{CA}-\mathrm{AKT}$ and KD-AKT sequences were generated using the bicistronicpQCXIP vector (Clontech) [28]. FGFR2 $\mathrm{C} 2$ and $\mathrm{C} 3$ cDNAs in pBabe retrovirus vector were a generous gift from Dr. Channing Der and have been described previously [41]. ER ab10 (Neomarker, Fremont, CA) and ER $\alpha$ sc-543 (Santa Cruz Biotechnology, Santa Cruz, CA) were used in combination for ChIP assay. The antibody against FGFR2 was from Santa Cruz Biotechnology. Antibody against FAS (clone CH11) was from Millipore (Temecula, CA). Keratinocyte Growth Factor (KGF) was purchased from R\&D Systems (Minneapolis, MN).

\section{Cell culture, retrovirus generation, and transfection}

MCF-7 cells were grown in MEM with $10 \%$ fetal calf serum (FCS), whereas Amphophenix cells were maintained in DMEM plus 10\% FCS. Retrovirus packaging and generation of MCF-7 cells overexpressing CA-AKT, KD-AKT, FGFR2 C2, and FGFR2 C3 have been described previously [28]. In all studies involving E2 treatment, cells were maintained in phenol red-free MEM plus 5\% dextran charcoal treated serum (CCS) for at least four days prior to experiments and all assays were done in this media. Single cell-derived MCF-7 clone and its tamoxifen and fulvestrant resistant variants of MCF-7 cells have been described previously and were gift from Dr. Ken Nephew [44].

\section{ExonHit splice array}

A microarray analysis of alternative splicing events covering a possible 10659 splice events of 893 apoptosis related genes was done using the array services of ExonHit Therapeutics, Inc. (Gaithersburg, MD). The splicing events analyzed include alternative splice acceptor (ASA), alternative splice donor (ASD), exon skipped (ES), exons skipped (EsS), intron retained (IR), novel exon (NE), novel exons (NEs), and partial internal exon deletion (PIED). RNA from untreated or E2 treated $\left(10^{-10} \mathrm{M}\right.$ for 3 hours) MCF-7p and MCF-7AKT cells were assayed in quadruplicate and those probes which gave difference between untreated and E2treated cells with a $p$ value from the ANOVA analysis of less than or equal to 0.001 were considered for further analysis.

\section{RNA isolation and quantitative reverse transcription polymerase chain reaction (qRT-PCR)}

RNA was isolated using the RNAeasy kit from Qiagen (Valencia, CA). qRT-PCR with specific primers was 
performed to measure the expression levels of wild type and splice variants. All qRT-PCR reactions were done using 2-5 independent RNA preparations. Mean and standard error of the mean (SE) are presented in the figures. Statistical evaluations were done using unpaired $t$ test (Graphpad.com). In some cases, results from experiments that showed extreme variability were excluded. Sequences of primers used for qRT-PCR are listed in Additional file 5.

\section{Chromatin immunoprecipitation assay (ChIP)}

ChIP-on-chip assay of MCF-7p and MCF-7AKT cells for ER $\alpha$ binding site has been described previously [28]. $E R \alpha$ binding to select genes that were alternatively spliced in response to E2 was verified by ChIP followed by real time PCR (ChIP-qPCR) as described previously [48]. The results presented are from two or more experiments. Since ChIP-qPCR is a very sensitive assay with wide experimental variability with respect to levels of E2-induced ER $\alpha$ binding, results of experiments that showed lower variability were selected for presentation.

\section{SiRNA transfection and western blotting}

siRNA against ER $\alpha$ and the control luciferase were purchased from Dharmacon (Lafayette, $\mathrm{CO}$ ) and transfected into cells using lipofectamine reagent. Protein extracts from transfected cells were prepared four days after transfection. Whole cell lysates from cells with or without E2 treatment for 24 hours were prepared in RIPA buffer and western blotting was preformed as described previously [61].

\section{Cell proliferation and cell death assays}

For cell proliferation, 2000 cells maintained in phenol redfree plus 5\% CCS containing media for four days were plated in the same media in each well of a 96-well plate overnight and then treated with indicated reagents for 26 days depending on the experiment. BromodeoxyuridineELISA (EMD Chemicals, Gibbstown, NJ) was used to measure cell proliferation. For cell death assay, cells were plated in a $60 \mathrm{~mm}$ plate and treated with indicated reagents for 48 hours. Cell death assay was performed using Annexin $\mathrm{V}$ labeling followed by flow cytometry as suggested by the manufacturer (Invitrogen).

\section{Additional files}

Additional file 1: E2-induced splice events common to MCF-7p and MCF-7AKT cells. This file describes E2-regulated splicing events common to MCF-7p and MCF-7AKT cells. In addition, this file also indicates ERa binding sites in the genes that undergo E2-regulated alternative splicing as well as the effect of E2 on expression of these genes in MCF-7p and MCF-7AKT cells. Furthermore, the early (three hours) and the late effects (24 hours) of E2 treatment on overall transcription of genes (extracted from NURSA website) are also shown. Longer version (LF) of the transcript in the array [reference (R) or the variant (V)] is also indicated. Positive number in fold change column indicates E2-induced splicing generating higher levels of the variant whereas negative number indicates repression of splicing event leading to generation of the variant. ASA, alternative splice acceptor; ASD; Alternative splice donor; ES, exon skipping; IR, intron retention; PEID, partial internal exon deletion.

Additional file 2: E2-induced splicing events observed in MCF-7p cells. This file is similar to Additional file 1 except that splicing events unique to MCF-7p cells are indicated.

Additional file 3: E2-induced splicing events observed in MCF-7AKT cells. This file is similar to Additional file 1 except that splicing events unique to MCF-7AKT cells are shown.

Additional file 4: Summary of ERa binding and E2-regulated expression of genes described in Additional file 1.

Additional file 5: Primer sequences used for qRT-PCR analyses.

\section{Abbreviations}

AXIN-1: Axis inhibition protein 1; CCS: Charcoal stripped serum; ChIP: Chromatin immunoprecipitation; ER: Estrogen receptor; ERE: Estrogen response element; FGFR2: Fibroblast growth factor receptor 2; hnRNP: Heterogeneous nuclear ribonuclear protein; KGF: Keratinocyte growth factor; PTB: Polypyrimidine tract binding protein; RRM: RNArecognition motif; RT-PCR: Reverse transcription polymerase chain reaction; SMRT: Silencing mediator of retinoic acid receptor and thyroid hormone receptor; SF2: Splicing factor 2; SR proteins: Serine/arginine-rich proteins; SRSF7: Serine/arginine-rich splicing factor 7 .

\section{Competing interests}

Authors declare that they have no competing interests.

\section{Authors' contribution}

PN performed several of the experiments described in Figures 1, 3, 4, 5, 6 and 7. E-K.S. performed experiments described in Figure 5 and RT-PCR analysis of CD44 minigene assay. NRC characterized AXIN-1 isoforms. VNU and AKD conducted intrinsic disorder prediction of splice isoforms. BWO provided reagents used in Figure 1 and provided intellectual input for these experiments. TRG, JSC, and MB were involved in ChIP-on-chip assay of MCF$7 \mathrm{p}$ and MCF-7AKT cells and the analysis of data derived from this assay. HN designed most of the experiments presented in this manuscript and wrote the manuscript. All authors read and approved the final manuscript.

\section{Acknowledgements}

We thank Drs. Frank Costantini for AXIN-1a and AXIN-1b expression vectors, Channing Der for FGFR2 cDNAs, and Ken Nephew for OHTR and Ful-R cells. $\mathrm{HN}$ is the Marian J. Morrison Professor of Breast Cancer Research.

\section{Funding}

This work is supported by a grant from the National Institutes of Health (CA89153) and Susan G. Komen for the Cure grant SAC110025. E-K. Song was supported by a post-doctoral fellowship from the Korea Science \& Engineering Foundation.

\section{Author details}

'Departments of Surgery, Indiana University School of Medicine, 980 West Walnut Street, Indianapolis, IN 46202, USA. ${ }^{2}$ Biochemistry and Molecular Biology, Indiana University School of Medicine, Indianapolis, IN 46202, USA. ${ }^{3}$ Center for Computational Biology and Bioinformatics, Indiana University School of Medicine, Indianapolis, IN 46202, USA. ${ }^{4}$ Department of Molecular and Cellular Biology, Indiana University School of Medicine Program in Bioinformatics, School of Informatics, Indiana University, Indianapolis, IN 46202, USA. ${ }^{5}$ Department of Medical Oncology, Baylor College of Medicine, Houston, TX 77030, USA. 'Dana-Farber Cancer Institute, Boston, MA 02115, USA. ${ }^{7}$ Current address: Department of Molecular Medicine, University of South Florida, College of Medicine, 12901 Bruce B. Downs Blvd, Tampa, FL 33612, USA. ${ }^{8}$ Amyris, Emeryville, CA 94608, USA. ${ }^{9}$ Cambridge Research Institute and Department of Oncology, Cancer Research UK, University of Cambridge, Robinson Way, Cambridge CB2 ORE, UK. 
Received: 29 January 2013 Accepted: 3 June 2013

Published: 11 June 2013

\section{References}

1. Ali S, Coombes RC: Endocrine-responsive breast cancer and strategies for combating resistance. Nat Rev Cancer 2002, 2:101-112.

2. Musgrove EA, Sutherland RL: Biological determinants of endocrine resistance in breast cancer. Nat Rev Cancer 2009, 9:631-643.

3. Rayala SK, Talukder AH, Balasenthil S, Tharakan R, Barnes CJ, Wang RA, Aldaz $M$, Khan S, Kumar R: P21-activated kinase 1 regulation of estrogen receptor-alpha activation involves serine 305 activation linked with serine 118 phosphorylation. Cancer Res 2006, 66:1694-1701.

4. Lee H, Bai W: Regulation of estrogen receptor nuclear export by ligandinduced and p38-mediated receptor phosphorylation. Mol Cell Biol 2002, 22:5835-5845.

5. Park KJ, Krishnan V, O'Malley BW, Yamamoto Y, Gaynor RB: Formation of an IKKalpha-dependent transcription complex is required for estrogen receptor-mediated gene activation. Mol Cell 2005, 18:71-82.

6. Campbell RA, Bhat-Nakshatri P, Patel NM, Constantinidou D, Ali S, Nakshatri H: Phosphatidylinositol 3-kinase/AKT-mediated activation of estrogen receptor alpha: a new model for anti-estrogen resistance. J Biol Chem 2001, 276:9817-9824.

7. Kato S, Endoh H, Masuhiro Y, Kitamoto T, Uchiyama S, Sasaki H, Masushige $\mathrm{S}$, Gotoh Y, Nishida E, Kawashima H, et al: Activation of the estrogen receptor through phosphorylation by mitogen- activated protein kinase. Science 1995, 270:1491-1494.

8. Wang ET, Sandberg R, Luo S, Khrebtukova I, Zhang L, Mayr C, Kingsmore SF, Schroth GP, Burge CB: Alternative isoform regulation in human tissue transcriptomes. Nature 2008, 456:470-476.

9. Shin C, Manley JL: Cell signalling and the control of pre-mRNA splicing. Nat Rev Mol Cell Biol 2004, 5:727-738.

10. Matlin AJ, Clark F, Smith CW: Understanding alternative splicing: towards a cellular code. Nat Rev Mol Cell Biol 2005, 6:386-398.

11. Blaustein M, Pelisch F, Tanos T, Munoz MJ, Wengier D, Quadrana L, Sanford $J R$, Muschietti JP, Kornblihtt AR, Caceres JF, et al: Concerted regulation of nuclear and cytoplasmic activities of SR proteins by AKT. Nat Struct Mol Biol 2005, 12:1037-1044.

12. Caceres JF, Kornblihtt AR: Alternative splicing: multiple control mechanisms and involvement in human disease. Trends Genet 2002, 18:186-193.

13. David CJ, Manley JL: Alternative pre-mRNA splicing regulation in cancer: pathways and programs unhinged. Genes Dev 2010, 24:2343-2364.

14. Whitman S, Wang X, Shalaby R, Shtivelman E: Alternatively spliced products CC3 and TC3 have opposing effects on apoptosis. Mol Cell Biol 2000, 20:583-593.

15. Gabut M, Samavarchi-Tehrani P, Wang X, Slobodeniuc V, O'Hanlon D, Sung HK, Alvarez M, Talukder S, Pan Q, Mazzoni EO, et al: An alternative splicing switch regulates embryonic stem cell pluripotency and reprogramming. Cell 2011, 147:132-146.

16. Venables JP, Klinck R, Koh C, Gervais-Bird J, Bramard A, Inkel L, Durand M, Couture S, Froehlich U, Lapointe E, et al: Cancer-associated regulation of alternative splicing. Nat Struct Mol Biol 2009, 16:670-676.

17. Venables JP, Klinck R, Bramard A, Inkel L, Dufresne-Martin G, Koh C, GervaisBird J, Lapointe E, Froehlich U, Durand M, et al: Identification of alternative splicing markers for breast cancer. Cancer Res 2008, 68:9525-9531.

18. Lapuk A, Marr H, Jakkula L, Pedro H, Bhattacharya S, Purdom E, Hu Z, Simpson K, Pachter L, Durinck S, et al: Exon-level microarray analyses identify alternative splicing programs in breast cancer. Mol Cancer Res 2010, 8:961-974.

19. Yoshida K, Sanada M, Shiraishi Y, Nowak D, Nagata Y, Yamamoto R, Sato Y, Sato-Otsubo A, Kon A, Nagasaki M, et al: Frequent pathway mutations of splicing machinery in myelodysplasia. Nature 2011, 478:64-69.

20. Romero PR, Zaidi S, Fang YY, Uversky VN, Radivojac P, Oldfield CJ, Cortese MS, Sickmeier M, LeGall T, Obradovic Z, Dunker AK: Alternative splicing in concert with protein intrinsic disorder enables increased functional diversity in multicellular organisms. Proc Natl Acad Sci USA 2006, 103:8390-8395.

21. Auboeuf D, Honig A, Berget SM, O'Malley BW: Coordinate regulation of transcription and splicing by steroid receptor coregulators. Science 2002, 298:416-419.
22. Auboeuf D, Dowhan DH, Dutertre M, Martin N, Berget SM, O'Malley BW: A subset of nuclear receptor coregulators Act as coupling proteins during synthesis and maturation of RNA transcripts. Mol Cell Biol 2005, 25:5307-5316

23. Dowhan DH, Hong EP, Auboeuf D, Dennis AP, Wilson MM, Berget SM, O'Malley BW: Steroid hormone receptor coactivation and alternative RNA splicing by U2AF65-related proteins CAPERalpha and CAPERbeta. Mol Cell 2005, 17:429-439.

24. Bittencourt D, Dutertre M, Sanchez G, Barbier J, Gratadou L, Auboeuf D: Cotranscriptional splicing potentiates the mRNA production from a subset of estradiol-stimulated genes. Mol Cell Biol 2008, 28:5811-5824.

25. Masuhiro Y, Mezaki Y, Sakari M, Takeyama K, Yoshida T, Inoue K, Yanagisawa J, Hanazawa S, O'Malley BW, Kato S: Splicing potentiation by growth factor signals via estrogen receptor phosphorylation. Proc Natl Acad Sci USA 2005, 102:8126-8131.

26. Koboldt DC: Comprehesive molecular portraits of humna breast cancers. Nature 2012, 490:61-70.

27. Ellis MJ, Ding L, Shen D, Luo J, Suman VJ, Wallis JW, Van Tine BA, Hoog J, Goiffon RJ, Goldstein TC, et al: Whole-genome analysis informs breast cancer response to aromatase inhibition. Nature 2012, 486:353-360.

28. Bhat-Nakshatri P, Wang G, Appaiah H, Luktuke N, Carroll JS, Geistlinger TR, Brown M, Badve S, Liu Y, Nakshatri H: AKT Alters genome-wide estrogen receptor alpha binding and impacts estrogen signaling in breast cancer. Mol Cell Biol 2008, 28:7487-7503.

29. Welboren WJ, van Driel MA, Janssen-Megens EM, van Heeringen SJ, Sweep FC, Span PN, Stunnenberg HG: ChIP-Seq of ERalpha and RNA polymerase II defines genes differentially responding to ligands. EMBO J 2009, 28:1418-1428.

30. Ochsner SA, Steffen DL, Hilsenbeck SG, Chen ES, Watkins C, McKenna NJ: GEMS (Gene Expression MetaSignatures), a Web resource for querying meta-analysis of expression microarray datasets: 17beta-estradiol in MCF-7 cells. Cancer Res 2009, 69:23-26.

31. Fullwood MJ, Liu MH, Pan YF, Liu J, Xu H, Mohamed YB, Orlov YL, Velkov S, Ho A, Mei PH, et al: An oestrogen-receptor-alpha-bound human chromatin interactome. Nature 2009, 462:58-64.

32. Haugsten EM, Wiedlocha A, Olsnes $\mathrm{S}$, Wesche J: Roles of fibroblast growth factor receptors in carcinogenesis. Mol Cancer Res 2010, 8:1439-1452.

33. Hunter DJ, Kraft P, Jacobs KB, Cox DG, Yeager M, Hankinson SE, Wacholder S, Wang Z, Welch R, Hutchinson A, et al: A genome-wide association study identifies alleles in FGFR2 associated with risk of sporadic postmenopausal breast cancer. Nat Genet 2007, 39:870-874.

34. Easton DF, Pooley KA, Dunning AM, Pharoah PD, Thompson D, Ballinger DG Struewing JP, Morrison J, Field H, Luben R, et al: Genome-wide association study identifies novel breast cancer susceptibility loci. Nature 2007, 447:1087-1093.

35. Moore MJ, Wang Q, Kennedy CJ, Silver PA: An alternative splicing network links cell-cycle control to apoptosis. Cell 2010, 142:625-636.

36. He X, Ee PL, Coon JS, Beck WT: Alternative splicing of the multidrug resistance protein 1/ATP binding cassette transporter subfamily gene in ovarian cancer creates functional splice variants and is associated with increased expression of the splicing factors PTB and SRp20. Clin Cancer Res 2004, 10:4652-4660.

37. Chen M, Manley JL: Mechanisms of alternative splicing regulation: insights from molecular and genomics approaches. Nat Rev Mol Cell Biol 2009, 10:741-754.

38. Busch A, Hertel KJ: Evolution of SR protein and hnRNP splicing regulatory factors. Wiley Interdiscip Rev RNA 2012, 3:1-12.

39. Salahshor S, Woodgett JR: The links between axin and carcinogenesis. J Clin Pathol 2005, 58:225-236.

40. Tawara M, Maeda T, Yamada Y, Harasawa H, Tsuruda K, Sugahara K, Moriuchi R, Tomonaga M, Kamihira S: Aberrant processing of Fas transcripts in adult T-cell leukemia: a possible role in tumor cell survival. Cancer Lett 2003, 193:235-242.

41. Cha JY, Lambert QT, Reuther GW, Der CJ: Involvement of fibroblast growth factor receptor 2 isoform switching in mammary oncogenesis. Mol Cancer Res 2008, 6:435-445.

42. Moffa AB, Ethier SP: Differential signal transduction of alternatively spliced FGFR2 variants expressed in human mammary epithelial cells. J Cell Physiol 2007, 210:720-731.

43. Itoh H, Hattori Y, Sakamoto H, Ishii H, Kishi T, Sasaki H, Yoshida T, Koono M, Sugimura T, Terada M: Preferential alternative splicing in cancer 
generates a K-sam messenger RNA with higher transforming activity. Cancer Res 1994, 54:3237-3241.

44. Fan M, Yan PS, Hartman-Frey C, Chen L, Paik H, Oyer SL, Salisbury JD, Cheng $A S, L i L, A b b o s h ~ P H$, et al: Diverse gene expression and DNA methylation profiles correlate with differential adaptation of breast cancer cells to the antiestrogens tamoxifen and fulvestrant. Cancer Res 2006 66:11954-11966.

45. Datta SR, Brunet A, Greenberg ME: Cellular survival: a play in three Akts. Genes Dev 1999, 13:2905-2927.

46. Schwerk C, Schulze-Osthoff K: Regulation of apoptosis by alternative premRNA splicing. Mol Cell 2005, 19:1-13.

47. Pritsker M, Doniger TT, Kramer LC, Westcot SE, Lemischka IR: Diversification of stem cell molecular repertoire by alternative splicing. Proc Natl Acad Sci USA 2005, 102:14290-14295.

48. Carroll JS, Meyer CA, Song J, Li W, Geistlinger TR, Eeckhoute J, Brodsky AS, Keeton EK, Fertuck KC, Hall GF, et al: Genome-wide analysis of estrogen receptor binding sites. Nat Genet 2006, 38:1289-1297.

49. Lin CY, Vega VB, Thomsen JS, Zhang T, Kong SL, Xie M, Chiu KP, Lipovich L, Barnett DH, Stossi F, et al: Whole-genome cartography of estrogen receptor alpha binding sites. PLoS Genet 2007, 3:e87.

50. Lupien MMC, Bailey ST, Eeckhoute J, Cook J, Westerling T, Zhang X, Carroll JS, Rhodes DR, Liu XS, Brown M: Growth factor stimulation induces a distinct ERalpha cistrome underlying breast cancer endocrine resistance. Genes Dev 2010, 24. in press.

51. Luco RF, Allo M, Schor IE, Kornblihtt AR, Misteli T: Epigenetics in alternative pre-mRNA splicing. Cell 2011, 144:16-26.

52. Raponi M, Kralovicova J, Copson E, Divina P, Eccles D, Johnson P, Baralle D, Vorechovsky I: Prediction of single-nucleotide substitutions that result in exon skipping: identification of a splicing silencer in BRCA1 exon 6. Hum Mutat 2011, 32:436-444

53. Auboeuf D, Dowhan DH, Kang YK, Larkin K, Lee JW, Berget SM, O'Malley BW: Differential recruitment of nuclear receptor coactivators may determine alternative RNA splice site choice in target genes. Proc Nat Acad Sci USA 2004, 101:2270-2274.

54. Jung DJ, Na SY, Na DS, Lee JW: Molecular cloning and characterization of CAPER, a novel coactivator of activating protein-1 and estrogen receptors. J Biol Chem 2002, 277:1229-1234.

55. Moffa AB, Tannheimer SL, Ethier SP: Transforming potential of alternatively spliced variants of fibroblast growth factor receptor 2 in human mammary epithelial cells. Mol Cancer Res 2004, 2:643-652.

56. Pond AC, Herschkowitz II, Schwertfeger KL, Welm B, Zhang Y, York B, Cardiff $\mathrm{RD}$, Hilsenbeck S, Perou CM, Creighton CJ, et al: Fibroblast growth factor receptor signaling dramatically accelerates tumorigenesis and enhances oncoprotein translation in the mouse mammary tumor virus-Wnt- 1 mouse model of breast cancer. Cancer Res 2010, 70:4868-4879.

57. Chalfant CE, Ogretmen B, Galadari S, Kroesen BJ, Pettus BJ, Hannun YA: FAS activation induces dephosphorylation of SR proteins; dependence on the de novo generation of ceramide and activation of protein phosphatase 1. J Biol Chem 2001, 276:44848-44855.

58. Nakamura T, Imai Y, Matsumoto T, Sato S, Takeuchi K, Igarashi K, Harada Y, Azuma Y, Krust A, Yamamoto Y, et al: Estrogen prevents bone loss via estrogen receptor alpha and induction of Fas ligand in osteoclasts. Cell 2007, 130:811-823.

59. Krum SA, Miranda-Carboni GA, Hauschka PV, Carroll JS, Lane TF, Freedman $L P$, Brown M: Estrogen protects bone by inducing Fas ligand in osteoblasts to regulate osteoclast survival. EMBO J 2008, 27:535-545.

60. Chen L, Park SM, Tumanov AV, Hau A, Sawada K, Feig C, Turner JR, Fu YX, Romero IL, Lengyel E, Peter ME: CD95 promotes tumour growth. Nature 2010, 465:492-49.

61. Bhat-Nakshatri P, Campbell RA, Patel NM, Newton TR, King AJ, Marshall MS, Ali S, Nakshatri H: Tumour necrosis factor and PI3-kinase control oestrogen receptor alpha protein level and its transrepression function. Br J Cancer 2004, 90:853-859.

doi:10.1186/1755-8794-6-21

Cite this article as: Bhat-Nakshatri et al:: Interplay between estrogen receptor and AKT in Estradiol-induced alternative splicing. BMC Medical Genomics 2013 6:21.

\section{Submit your next manuscript to BioMed Central and take full advantage of:}

- Convenient online submission

- Thorough peer review

- No space constraints or color figure charges

- Immediate publication on acceptance

- Inclusion in PubMed, CAS, Scopus and Google Scholar

- Research which is freely available for redistribution 